Diabetologia (1994) 37: 885--888

Diabetologia

(C) Springer-Verlag 1994

\title{
Impaired skeletal muscle glycogen synthase activation by insulin in the Goto-Kakizaki (G/K) rat
}

\author{
C. Villar-Palasi ${ }^{1}$, R. V.Farese ${ }^{2}$ \\ ${ }^{1}$ Department of Pharmacology, University of Virginia School of Medicine Charlottesville, Virginia, USA \\ 2 J. A. Haley Veterans' Hospital, Departments of Internal Medicine and Biochemistry, University of South Florida College of \\ Medicine, University of South Florida, Tampa, Florida USA
}

Summary The Goto-Kakizaki (G/K) rat is an animal model of non-insulin-dependent diabetes mellitus, with early hyperglycaemia, hyperinsulinaemia, and insulin resistance. We have studied the effect of insulin on the activation of glycogen synthase in the $\mathrm{G} / \mathrm{K}$ rat and in the original parent strain, the Wistar rat. After insulin injection, glycogen synthase I activity, glycogen synthase phosphatase activity and glucose 6-phosphate content in skeletal muscle were significantly increased in the Wistar rats. In the G/K rats, insulin injection resulted in a reduced activation of skeletal muscle glycogen synthase, which was not significant when compared with the control rats without insulin, and no increases in glycogen synthase phospha- tase and glucose 6-phosphate were seen. In adipose tissue the activation of glycogen synthase by insulin was normal in the $\mathrm{G} / \mathrm{K}$ rats. Previous investigations have shown that glucose disappearance rates are low in the G/K rat. However, stimulation of glucose transport was reported to be normal in the G/K rat. A defective activation of glucose accumulation into glycogen by skeletal muscle may contribute to explain the hyperglycaemia in the $\mathrm{G} / \mathrm{K}$ rat. [Diabetologia (1994) 37: 885-888]

Key words Glycogen synthase, insulin, Goto-Kakizaki rat, non-insulin-dependent diabetes mellitus, phosphatase, glucose 6-phosphate, skeletal muscle.
The $\mathrm{G} / \mathrm{K}$ rat is a non-obese animal model of NIDDM produced by selective breeding of hyperglycaemic rats repeated over 35 generations starting with a colony of non-diabetic Wistar rats $[1,2]$. The main characteristics are an early increase in plasma glucose, impaired glucose tolerance which neither deteriorates nor improves with age, poor insulin secretory response to glucose in vivo, compared with the parent Wistar strain, and higher basal insulin secretion than in Wistar controls. G/K rats manifest increased activ-

Received: 26 November 1993

and in revised form: 26 April 1994

Corresponding author: Dr. C. Villar-Palasi, University of Virginia, Health Sciences Center, MR4 Building, Room 5012, Lane Road, Charlottesville, VA 22908, USA

Abbreviations: DTT, Dithiothreitol; TLCK, tosyl lysyl chloromethyl ketone; GSPase, glycogen synthase phosphatase; G3PAT, glycerol-3-phosphate acyl transferase; G/K, Goto-Kakizaki rat; IPG, Inositolphosphoglycan. ity of the hepatic glycolytic and gluconeogenic pathways, indicating insulin resistance. Although the hyperglycaemia is moderate, neuropathy and glomerulopathy are present [3]. Interestingly, in common with human patients with NIDDM [4] and with another animal model of NIDDM, the macaca mulatta monkey [5], the $G / K$ rat shows deficient urinary chiroinositol levels [6]. Chiroinositol is an essential component of a putative insulin mediator which reproduces in vitro the effects of insulin on the activation of pyruvic dehydrogenase [7] and G3PAT (unpublished observations), and may also activate glucose transport in intact cells [8].

Although this animal model of NIDDM has been known for many years, some of the best metabolic parameters of insulin action have not been studied. In particular, the effect of insulin on muscle glycogen synthase, of great importance in glycaemic control has not received attention. Here we report the results of comparative studies on the activation by insulin of glycogen synthase in the G/K rat and in normal 
Table 1. Effects of insulin injection on Wistar and G/K rats

\begin{tabular}{|c|c|c|c|c|c|c|}
\hline & \multicolumn{3}{|l|}{ Wistar } & \multicolumn{3}{|l|}{$\mathrm{G} / \mathrm{K}$} \\
\hline & Control & Insulin & $\%$ Increase & Control & Insulin & $\%$ Increase \\
\hline Glycogen synthase $\mathrm{I}(\%)$ & 19.1 & 29.5 & $54.4^{\mathrm{a}}$ & 15.3 & 18.6 & $21.5^{b}$ \\
\hline Glycogen synthase phosphatase & 604 & 1039 & $72.0^{\mathrm{a}}$ & 476 & 488 & $2.5^{\mathrm{b}}$ \\
\hline Glucose 6-phosphate $(\mathrm{mmol} / \mathrm{l})$ & 0.31 & 0.53 & $71.0^{\mathrm{a}}$ & 0.27 & 0.31 & $14.8^{\mathrm{b}}$ \\
\hline
\end{tabular}

Wistar rat values, average of ten control and ten insulin-injected rats; $\mathrm{G} / \mathrm{K}$ rat values, average of six animals in each group. ${ }^{\mathrm{a}} p<0.0005 ;{ }^{\mathrm{b}} p>0.15$

Wistar rats, as well as in the mechanisms of activation of the synthase.

\section{Materials and methods}

Treatment of the animals. Wistar rats were obtained from Hilltop Nurseries (Scottdale, PA, USA). A diabetic G/K rat colony using animals obtained from Drs. S. Suzuki and T. Toyota, established in the James A. Haley VA Hospital in Tampa, Fla, USA, was used as a source for the diabetic animals. Average blood glucose in the $\mathrm{G} / \mathrm{K}$ rats was $8.6 \mathrm{mmol} / \mathrm{l}$, and plasma insulin was about $20 \mu \mathrm{U} / \mathrm{ml}$, or approximately twice the levels of the Wistar rats. For the experiments, fed, male, Wistar rats, about $200 \mathrm{~g}$, and G/K rats, 150-200 g weight, were deeply anaesthetised by i.p. injection of pentobarbital. Fifteen minutes later, either $1 \mathrm{mg}$ propranolol/kg (control rats) or 2 I. U. insulin, $1 \mathrm{mg}$ propranolol, $140 \mathrm{mg}$ glucose $/ \mathrm{kg}$ (insulin-treated rats) were injected by the tail vein. For the G/K rats, six were used as controls and six were insulin-injected; ten Wistar rats were used for each condition. Five minutes after the injection, the skin covering the hind legs was removed, and 7 min after the i.v. injection, muscle of the hind legs was removed and immediately (less than $5 \mathrm{~s}$ ) frozen using Wallemberg clamps chilled in liquid $\mathrm{N}_{2}$. No hypoglycaemia was observed in any of the insulin-injected animals at the end of the experiment.

The muscle was powdered in stainless-steel mortars also chilled with liquid $\mathrm{N}_{2}$, and kept constantly frozen at $-180^{\circ} \mathrm{C}$. Extracts were prepared and tested the same day, except for the assay of glucose 6-phosphate, which required lyophilization of the extracts. All results reported were obtained from the same animals. All individual values are average of duplicate determinations.

Enzymes and assay procedures. Glycogen synthase I was purified from rabbit skeletal muscle by the method of Takeda et al. [9] and was ${ }^{32} \mathrm{P}$-phosphorylated with rabbit liver casein kinase 1 and isolated as described previously [10]. For the assay of glucose 6-phosphate in muscle, $1 \mathrm{~g}$ aliquots of frozen tissue were homogenized in $6 \mathrm{ml}$ of $10 \%$ trifluoroacetic acid, centrifuged at $20000 \times \mathrm{g}$ for $20 \mathrm{~min}$, and the supernatants lyophilized. The residue was dissolved in distilled water, lyophilized and re-dissolved at least four times, neutralized, and finally dissolved in $1 \mathrm{ml}$ distilled water/g muscle. The solutions were filtered through $0.22-\mu \mathrm{m}$ cellulose acetate filters and glucose 6phosphate was determined with glucose 6-phosphate dehydrogenase and NADP in $0.2 \mathrm{ml}$ of filtrate, as described by Kornberg [11]. To normalize the extracts, aliquots of the filtrates were diluted 1:100 in water and the absorption read at $260 \mathrm{~nm}$. At this wave length the absorption, due to the extracted nucleotide bases, is constant per gram of tissue. The average absorption of the $1: 100$ dilutions was $0.996 \pm 0.012 / \mathrm{g}$ muscle. For convenience it was considered 1.000 .

Glycogen synthase activity was assayed by the method of Thomas et al. [12], using (in mmol/1) 6.7 UDP-[UL] ${ }^{14} \mathrm{C}$-glu- cose (127 cpm/nmol), $10 \mathrm{mg}$ glycogen/ml, 50 Tris- $\mathrm{HCl}, \mathrm{pH} 7.8$, 20 EDTA, 50 potassium fluoride, and \pm 10 glucose 6 -phosphate. Tissues were homogenized in a Polytron for $20 \mathrm{~s}$ with 7 volumes (for skeletal muscle) or 1 volume (for fat pads) of 50 Tris $(10 \%$ glycerol, 150 potassium fluoride, 15 EDTA, 5 DTT, 1 benzamidine, $2 \mathrm{mg}$ glycogen $/ \mathrm{ml}, 0.1 \mathrm{TLCK}, 2.5 \mu \mathrm{g}$ leupeptin/ml) pH 7.96 at room temperature (Buffer T). The homogenates were centrifuged at $3000 \times g$ for $20 \mathrm{~min}$, and glycogen synthase activity $\pm 10 \mathrm{mmol} / \mathrm{l}$ glucose 6 -phosphate measured in $20 \mu \mathrm{l}$ of supernatant plus $40 \mu \mathrm{l}$ of test mixture, $10 \mathrm{~min}$ incubation at $30^{\circ} \mathrm{C}$. All the tests were run in duplicate.

For the assay of glycogen synthase phosphatase activity, aliquots of frozen muscle were homogenized in a Polytron for 20 seconds with 2 volumes (w/v) of (in mmol/l) $50 \mathrm{MOPS}$, (10\% glycerol, 5 EDTA, 2 EGTA, 2 mg glycogen $/ \mathrm{ml}$, 1 benzamidine, 0.1 TLCK, $2.5 \mu \mathrm{g}$ leupeptin/ml) pH 7.35 (buffer M). The homogenates were centrifuged at $3000 \times g$ for $20 \mathrm{~min}$ and the supernatants filtered through glass wool. Phosphatase activity of the extracts was measured by the release of ${ }^{32} \mathrm{P}$ from ${ }^{32} \mathrm{P}$-labelled glycogen synthase, as described by Kato and Bishop [13] and modified as described previously [10]. Activity is expressed as cpm released from ${ }^{32} \mathrm{P}$-labelled glycogen synthase per mg of protein in the extracts.

The effect of insulin on hexose transport was measured in the gastrocnemius muscles of anaesthetized rats after euglycaemic $\left(150 \mathrm{mg}\right.$ of either $\left[{ }^{3} \mathrm{H}\right] \mathrm{D}$-glucose or $\left[{ }^{3} \mathrm{H}\right]$ 2-deoxiglucose $/ 100 \mathrm{ml}$ plasma), hyperinsulinemic $\left(40 \mathrm{mU} \cdot \mathrm{kg}^{-1} \cdot \mathrm{min}^{-1}\right)$ clamps. Tracer ${ }^{14} \mathrm{C}[\mathrm{UL}] \mathrm{L}$-glucose, not transported, was perfused to correct for extra-cellular space. At the end of the perfusion, the tissues were solubilized and the uptake of radioactivity determined basically as described by Turinsky et al. [14].

\section{Results}

Activation of glycogen synthase by insulin. Insulin injection resulted in activation of skeletal muscle glycogen synthase in the Wistar rats. The average glycogen synthase I content in the controls was $19.1 \pm 0.5 \%$, and in the insulin-injected animals $29.5 \pm 2.4 \%$, an increase of $54.5 \%, p$ value 0.0005 . In contrast, in the $\mathrm{G} /$ $\mathrm{K}$ rats, the controls averaged $15.3 \pm 1.4 \%$, and the insulin-injected rats $18.6 \pm 1.6 \%$, an increase of $21.5 \%$, but not attaining significance $(p=0.157)$, Table 1 . Furthermore, the average total glycogen synthase in the $\mathrm{G} / \mathrm{K}$ rat muscle extracts, $16.3 \pm 2.1 \mathrm{nmol} \cdot \mathrm{mg}$ protein $^{-1} \cdot \min ^{-1}$, was significantly lower $(p=0.028)$ than in the Wistar rat muscle extracts, $24.2 \pm 2.4 \mathrm{nmol} \cdot \mathrm{mg}$ protein $^{-1} \cdot \mathrm{min}^{-1}$. In fat pads of $\mathrm{G} / \mathrm{K}$ rats, however, the activation of glycogen synthase by insulin was much higher: the control glycogen synthase I averaged 
$8.1 \pm 1.7 \%$, and in the insulin-treated rat samples $31.4 \pm 18.1 \%$, an increase of $387 \%$, and comparable to the activation observed in Wistar rats, $15.1 \pm 3.6 \%$, control, $48.2 \pm 11.0 \%$ insulin injected, $319 \%$ increase.

Effect of insulin on the glucose 6-phosphate content of skeletal muscle. In the insulin-injected Wistar rats the concentration of glucose 6-phosphate averaged $0.53 \pm 0.03 \mu \mathrm{mol} / \mathrm{g}$ wet tissue, an increase of $64.3 \%$ over the controls $(0.31 \pm 0.02 \mu \mathrm{mol} / \mathrm{g})$. The $\mathrm{G} / \mathrm{K}$ rats had similar basal levels, $0.27 \pm 0.03 \mu \mathrm{mol} / \mathrm{g}$ (Table 1 ), but after insulin injection, the concentration did not show any significant increase $(0.31 \pm 0.01 \mu \mathrm{mol} / \mathrm{g}$ $[p=0.997])$.

Activation of synthase phosphatase activity by insulin. The effect of insulin injection on the synthase phosphatase activity of concentrated muscle extracts was measured as described in the Methods section. In the Wistar rats, the dephosphorylation of ${ }^{32} \mathrm{P}$-labelled glycogen synthase by concentrated muscle extracts was $72 \%$ higher in the insulin-injected rats than in the controls $(1039 \pm 64 \mathrm{cpm} / \mathrm{mg}$ protein in the extracts of insulin-injected rats; $604 \pm 46 \mathrm{cpm} / \mathrm{mg}$ protein in the control extracts). In the $\mathrm{G} / \mathrm{K}$ rats, the basal phosphatase activity was significantly lower $(p=0.04)$ than in the Wistar rats, and insulin injection did not cause any significant increase in phosphatase activity $(476 \pm 23 \mathrm{cpm} / \mathrm{mg}$ protein muscle control extracts; $488 \pm 18 \mathrm{cpm} / \mathrm{mg}$ protein in extracts from insulin-treated rats, $p=0.7$ ).

The comparative results from the three determinations are presented in Table 1.

\section{Discussion}

There is a clear impairment of the activation of skeletal muscle glycogen synthase by insulin in the $\mathrm{G} / \mathrm{K}$ rats when compared with the response of the parent strain, the Wistar rats. In agreement with previous reports on the muscle glycogen synthase activity in diabetic patients [15], the $G / K$ rats have a lower total glycogen synthase activity and basal per cent synthase I $(p=0.03)$ than the Wistar rats. The defect in the $\mathrm{G} / \mathrm{K}$ rats appears complex, because not only is there no activation of glycogen synthase phosphatase, but also the control levels of phosphatase are lower in the $\mathrm{G} / \mathrm{K}$ rat. Decreases in basal muscle glycogen synthase phosphatase activity have been reported in diabetic rabbits [16], and low activities of phosphatase as well as little or no response to insulin have been reported in NIDDM patients in NIDDM [17].

The elevated plasma glucose concentrations in the $\mathrm{G} / \mathrm{K}$ rat do not appear to be due to a defect in the activation of the insulin receptor. The effect of insulin on $\left[{ }^{3} \mathrm{H}\right]$ 2-deoxyglucose uptake in muscles in 10-min perfusions and in isolated adipocytes of Wistar and $\mathrm{G} / \mathrm{K}$ rats, determined as described, and expressed as per cent increase over controls, appear to be practically identical. However, in the G/K rat, D-glucose uptake by isolated gastrocnemius, tested by the same method in perfusions of up to $1-\mathrm{h}$, is only about $50 \%$ of that observed with Wistar rats, and this defect correlates with the defective activation of glycogen synthase. It has been reported that various isolated tissues from the $\mathrm{G} / \mathrm{K}$ rat are less reactive to the effect of insulin on glucose uptake than corresponding tissues in the control rat, particularly muscles with a high percentage of glycolytic fibres [18]. Disappearance rates calculated from glucose tolerance tests [19] or following i.p. glucose injection [20] have shown a marked impairment in the $\mathrm{G} / \mathrm{K}$ rat, probably related to a decreased glucose-stimulated insulin release by the pancreas [19]. The defect in insulin secretion, coupled with the presently found defects in glucose uptake and in glycogen synthase activation, may possibly account for the hyperglycaemia in the $\mathrm{G} / \mathrm{K}$ rat.

The activation by insulin of glycogen synthase appears essentially normal in epididymal fat pads of the $\mathrm{G} / \mathrm{K}$ rat. In contrast, defective activation of G3PAT by insulin, as well as by chiroinositol-containing insulin mediators was found in adipocytes from $\mathrm{G} / \mathrm{K}$ rats. However, if the $\mathrm{G} / \mathrm{K}$ rats were treated for several days with insulin, the chiroinositol IPG mediator was found to activate G3PAT in cell-free homogenates of adipocytes, but, again, insulin alone had no effect (unpublished observations). Therefore, it would appear that different pathways of activation by insulin act upon G3PAT and glycogen synthase in adipose tissue, and that metabolic defects may affect only particular enzymes. In broken cell preparations insulin activates G3PAT, but not glycogen synthase, in agreement with the idea that at least two different pathways of metabolic activation are stimulated following insulin treatment.

In conclusion, the G/K rat appears to be an appropriate animal model of NIDDM in that there is a defective response of glycogen synthase activation by insulin. It differs from typical NIDDM in that the hyperglycaemia appears early in the life of the animals, and the rats are lean, not obsese. A typical defect in the activation of glycogen synthase by insulin appears to be present in muscle, but not adipose tissue. Concomitant decreases in glycogen synthase activity and activation by insulin, as well as low concentrations of glucose 6-phosphate, are also found in the $\mathrm{G} / \mathrm{K}$ rat muscle. 


\section{References}

1. Goto Y, Kakizaki M, Masaki N (1975) Spontaneous diabetes produced by selective breeding of normal Wistar rats. Proc Jpn Acad 51: 80-85

2. Goto Y, Kakizaki M (1981) The spontaneous-diabetic rat: a model of non-insulin dependent diabetes mellitus. Proc Jpn Acad 57: 381-384

3. Yagihashi S, Tonosaki A, Yamada K-I, Kakizaki M, Goto Y (1982) Peripheral neuropathy in selectively-inbred spontaneously diabetic rats: electrophysiological, morphometrical and freeze-replica studies. Tohoku J Exp Med 138: 39 48

4. Kennington AS, Hill CR, Craig J et al. (1990) Low urinary chiro-inositol excretion in non insulin-dependent diabetes mellitus. New Eng J Med 323: 373-378

5. Ortmeter HK, Bodkin NL, Lilley K, Larner J, Hansen BC (993) Chiroinositol deficiency and insulin resistance I. Urinary excretion rate of chiroinositol is directly associated with insulin resistance in spontaneously diabetic rhesus monkeys. Endocrinology 132: 640-645

6. Suzuki S, Taneda Y, Hirai S et al. (1991) Molecular mechanism of insulin resistance in spontaneous diabetic GK (Goto-Kakizaki) rats. In: Sakamoto N, Angel A, Hotta N (eds) New directions in research and clinical works for obesity and diabetes mellitus. Elsevier Science, New York, pp 197-203

7. Larner J, Huang LC, Schwartz CF et al. (1988) Rat liver insulin mediator which stimulates pyruvate dehydrogenase phosphatase contains galactosamine and D-chiroinositol. Biochem Biophys Res Commun 151: 1416-1426

8. Machicao F, Mushack J, Seffer E, Ermel B, Haring HU (1990) Mannose, glucosamine, and inositol monophosphate inhibit the effects of insulin on lipogenesis. Biochem J 266: 909-916

9. Takeda Y, Brewer HB, Larner J (1975) Structural studies on rabbit muscle glycogen synthase. 1 Subunit composition J Biol Chem 250: 8943-8950
10. Villar-Palasi C (1991) Substrate specific activation by glucose 6-phosphate of the dephosphorylation of muscle glycogen synthase. Biochim Biophys Acta 1095: 261-267

11. Kornberg A (1950) Enzymatic synthesis of triphosphopyridine nucleotide. J Biol Chem 182: 805-813

12. Thomas JA, Schlender KK, Larner J (1968) A rapid filter paper assay for UDP-glucose-glycogen glucosyltransferase. Including an improved biosynthesis of $\mathrm{UDP}^{14} \mathrm{C}$ glucose. Anal Biochem 25: 486-499

13. Kato K, Bishop JS (1972) Glycogen synthase D phoshatase. I Some new properties of the partially purified enzyme from rabbit skeletal muscle. J Biol Chem 247: 74207429

14. Turinsky J, Bayly BP, O'Sullivan DM (1990) 1,2-Diacylglycerol and ceramide levels in rat skeletal muscle and liver in vivo. Studies with insulin, exercise, muscle denervation and vasopressin. J Biol Chem 265: 7933-7938

15. Kelley DE, Moran M, Mandarino LJ (1993) Metabolic pathways of glucose in skeletal muscle of lean NIDDM patients. Diabetes Care 16: 1158-1166

16. Khatra BS (1984) Properties of a phosphoprotein phosphatase from skeletal muscle and its regulation in diabetes. Proc Soc Exp Biol Med 177: 33-41

17. Kida Y, Esposito-Del Puente A, Bogardus C, Mott DM (1990) Insulin resistance is associated with reduced fasting and insulin stimulated glycogen synthase phosphatase activity in human skeletal muscle. J Clin Invest 85: 476-481

18. Bisbis S, Bailbe D, Tormo M-A et al. (1993) Insulin resistance in the GK rat: decreased receptor number but normal kinase activity in liver. Am J Physiol 265: E807-E813

19. Portha B, Serradas P, Bailbe D, Suzuki K-I, Goto Y, Giroix MH (1991) $\beta$-cell insensitivity to glucose in the GK rat, a spontaneous non-obese model for type II diabetes. Diabetes 40: 486-491

20. Ostenson C-G, Abdel-Halim SM, Rasschaert J et al. (1993) Deficient activity of FAD-linked glycerophosphate dehydrogenase in islets of GK rats. Diabetologia 36: 722-726 